\title{
The Risk of Mortality or Cerebral Palsy in Twins: A Collaborative Population-Based Study
}

\author{
ANN I. SCHER, BEV PETTERSON, EVE BLAIR, JONAS H. ELLENBERG, JUDY K. GRETHER, ERIC HAAN, \\ DINAH S. REDDIHOUGH, MARSHALYN YEARGIN-ALLSOPP, AND KARIN B. NELSON
}

\begin{abstract}
Neuroepidemiology Branch, National Institute of Neurological Disorders and Stroke [A.I.S., K.B.N.], National Institutes of Health, Bethesda, MD, U.S.A.; Child Health Research, Subiaco, Western Australia and Department of Anatomy and Human Biology [B.P.], University of Western Australia, Nedlands; Institute for Child Health Research [E.B.], Western Australia; Westat [J.H.E.], Rockville, Maryland; California Birth Defects Monitoring Program [J.K.G.], Emeryville, California; South Australian Cerebral Palsy Register, Women's and Children's Hospital [E.H.], North Adelaide, South Australia; Royal Children's Hospital [D.S.R.], Melbourne, Victoria; National Center on Birth Defects and Developmental Disabilities, Centers for Disease Control and Prevention [M.Y-A.], Atlanta, Georgia
\end{abstract}

\begin{abstract}
The purpose of the paper was to describe demographic and clinical factors associated with fetal or neonatal death or cerebral palsy (CP) in twins. Vital statistics from five populations in the United States and Australia, which included information on CP diagnosed after $1 \mathrm{y}$ of age. Information on zygosity was not available. In 1,141,351 births, 25,772 of whom were twins, significant secular trends from 1980 to 1989 included increasing prevalence of twins, increasing proportion of unlike-sex twins, and increasing maternal age. Overall, twins were at an approximately 5-fold increased risk of fetal death, 7-fold increased risk of neonatal death, and 4-fold increased risk of CP compared with singletons. However, at birth weight $<2500 \mathrm{~g}$, twins generally did better than singletons, both with respect to mortality and to $\mathrm{CP}$ rates. Second-born twins and twins from same-sex pairs were at increased risk of early death but not of CP. Twins from growth-discordant pairs and twins whose co-twin died were at
\end{abstract}

\section{ABSTRACT}

increased risk of both mortality and $\mathrm{CP}$. The highest rates of $\mathrm{CP}$ were in surviving twins whose co-twin was still-born $(4.7 \%)$, died shortly after birth $(6.3 \%)$ or had CP $(11.8 \%)$. In this large data set spanning a 10 -y period, overall rates of death or cerebral palsy were higher in twins than singletons, although small twins generally did better than small singletons. Co-twin death was a strong predictor of CP in surviving twins. This risk was the same for same- and different-sex pairs, and observed both for preterm and term infants. (Pediatr Res 52: 671-681, 2002)
CP, cerebral palsy
DZ, dizygous
MZ, monozygous
$\mathbf{O R}$, odds ratio

TTTS, twin-twin transfusion syndrome
The prevalence of multiple births has increased in recent years (1-3), making the identification of factors that influence outcome in these infants increasingly important from a public health perspective. Infants from multiple births are known to be at higher risk of cerebral palsy (CP) than singleton infants (4-7). As the risk of CP is strongly related to low birth weight or immaturity, and twin infants are on average smaller and born earlier than singleton infants, it is necessary to separate the influence of birth weight from other factors which may independently predict unfavorable outcome.

Received June 26, 2001; accepted April 15, 2002.

Correspondence: Ann I. Scher, Ph.D., Laboratory of Epidemiology, Demography, and Biometry, National Institute on Aging, 7201 Wisconsin Ave, Suite 3C-309, MSC 9205, Bethesda, MD 20892-9205; e-mail: schera@mail.nih.gov

DOI: 10.1203/01.PDR.0000032159.88318.5B
The aim of this study is to describe the risk of CP in a large population-based cohort of over one million births, of whom more than 20,000 were twins. Our data came from five populations in Australia and the United States (9).* Demographic characteristics were derived from birth records and supplemented by perinatal death certifications and $\mathrm{CP}$ diagnoses obtained from registers with a high ascertainment of cases.

Twins are more likely than singletons to die as infants (4, $8-10$ ), precluding a diagnosis of CP which generally cannot be made with confidence until months or years after birth. Our primary purpose was to explore factors related to $\mathrm{CP}$ risk in

\footnotetext{
*Western Australian Maternal and Child Health Research Database, South Australian Pregnancy Outcome Statistics Unit, Victorian Consultative Council on Obstetric and Paediatric Mortality and Morbidity and Victorian Cerebral Palsy Register, California Birth Defects Monitoring Program, Centers for Disease Control and Prevention.
} 
twins. It was necessary, therefore, to examine factors associated with the competing risk, which is early mortality.

\section{METHODS}

Vital statistics collected during the decade of the 1980s from five populations in the United States and Australia were combined for analysis of mortality and neurologic morbidity in multiple births. The three Australian populations consisted of all births from Western Australia, Victoria, and South Australia. The North American populations were from California (four counties in the San Francisco Bay area) and Georgia (five counties from the Metropolitan Atlanta area). Singleton and twin births only were included. Detailed descriptions of the individual datasets can be found in the following references: Western Australia (Stanley et al. 1994) (11); Victoria (Beischer et al. 1990) (12); South Australia (Chan et al. 1986, Byron-Scott et al. 1997) (13, 14); California (Grether et al. 1992) (15); and Georgia (Boyle et al. 1991, Adams et al. 1997) (16-18).

Cerebral Palsy diagnoses in the Georgia dataset were from the Metropolitan Atlanta Developmental Disabilities Surveillance Program. Cerebral Palsy was diagnosed at age 3 to 10 , and was defined as "a group of nonprogressive, but often changing, motor impairment syndromes secondary to lesions or anomalies of the brain arising at any time during brain development. The impairment of motor function may result in paresis, involuntary movement, or incoordination." Children with postnatally acquired CP diagnosed before $11 \mathrm{y}$ of age were included. Excluded were motor disorders which are transient, a result of progressive disease of the brain, or which are due to spinal cord abnormalities or injuries. CP diagnoses were limited to children with known plurality. In the California CP registry (15), CP was defined as "a chronic disability of CNS origin characterized by aberrant control of movement or posture, appearing early in life and not as the result of a progressive disease." Children were ascertained at the age of 3 , and instances of $\mathrm{CP}$ due to infection or other adverse event after the first $28 \mathrm{~d}$ of life were not included. CP was ascertained at age 5 in the Australian registries and defined in a similar manner as California. CP diagnoses were available for all infants in the Victorian and Western Australian populations and twin infants only in the South Australian population.

Each entry in the database corresponded to an individual birth, not pregnancy. Thus, each twin had a separate entry in the database. The following data were available: birth weight, gestational age, gender, plurality, maternal race (except for Victoria), maternal age, and birth order (for twins). Entries with unknown birth weight or with an invalid gestational age (defined as less than $20 \mathrm{wk}$, more than $46 \mathrm{wk}$, or unknown) were excluded from further analysis except where noted. The following outcomes were recorded: stillbirth, death $<28 \mathrm{~d}$, death $\leq 1 \mathrm{y}$, and cerebral palsy. In some cases, the birth weight for gestational age data were implausible, particularly when the gestational age was very early. We chose not to exercise arbitrary rules of exclusion as these inevitably impose bias.
However, our assumption is that birth weight is more likely to be correct than gestational age.

Almost all $(99.6 \%)$ of the twins were matched to their co-twins. For these twins, the same demographic and outcome data were available for the co-twin, e.g. co-twin sex, co-twin birth weight, and co-twin outcome (stillbirth, neonatal death, postneonatal death $<1 \mathrm{y}$, or cerebral palsy). Each matched twin was classified as being either in a same-sex pair or a different-sex pair. Four types of twins were defined: twins from male-only pairs (M:M), twins from female-only pairs (F:F), female twins from mixed-sex pairs (F:M) and male twins from mixed-sex pairs (M:F). A twin was defined as growth discordant if the absolute difference in birth weight between twin and co-twin exceeded $20 \%$ of the larger twins' birth weight. To distinguish between growth discordance due to the fetal death of one co-twin from growth discordance due to other reasons, analysis was restricted to growth discordant pairs with both twins liveborn except where otherwise noted.

Crude rates of mortality and $\mathrm{CP}$ were calculated overall and by demographic and twin factors. Mortality rates include stillbirth and death within $28 \mathrm{~d}$ of birth, and were calculated as a percentage of all births (live births and still births). Rates of CP were calculated as a percentage of all infants alive at $1 \mathrm{y}$. Univariate and multivariate analyses were performed using Intercooled Stata 6.0 (Stata, Corp). Univariate comparisons were made using t-tests and $\chi^{2}$ tests as appropriate. The $p$-values considered statistically significant were modified to avoid the problem of multiple comparisons as indicated. Linear changes in study variables over the time frame of the study (1980-1989) were assessed using a nonparametric trend test (Stata, nptrend) (19). Logistic regression was used to calculate adjusted prevalence rate ratios (odds ratios) for some demographic and twin factors after adjustment for birth weight and gestational age where noted. In these logistic models, birth weight was modeled using four terms (bwt, bwt ${ }^{(2)}$, bwt ${ }^{(3)}$, bwt ${ }^{(4)}$ and gestational age was modeled using two terms $\left(\mathrm{ga} \mathrm{ga}^{2}\right)$ in an effort to find the best fit for the observed nonlinear association of these primary factors on the outcomes of interest. To allow for the nonindependence of data from multiple births, $p$-values were calculated using a robust variance calculation in comparisons using the logistic model and for other comparisons ( $t$ tests, $\chi^{2}$ tests), twin pairs were treated as a single sampling unit for purposes of variance computations.

\section{RESULTS}

Information on 1,142,252 births was available from the three Australian and two American populations. Of these, 1,141,351 were singletons or twins. Table 1 shows maternal and singleton/twin characteristics for the individual populations for the years covered by the study. The non-Caucasian population for the regions was as follows, excluding those with unknown race or "other" race: Western Australia: 5.1\% Aboriginal; South 
Table 1. Characteristics of the Individual Data Sets

\begin{tabular}{|c|c|c|c|c|c|c|c|c|c|c|c|c|c|c|}
\hline \multirow[b]{2}{*}{ Location } & \multirow[b]{2}{*}{$n$} & \multirow[b]{2}{*}{$\begin{array}{l}\text { Birth } \\
\text { Years }\end{array}$} & \multirow{2}{*}{$\begin{array}{c}\text { Average } \\
\text { birth } \\
\text { weight } \\
\text { (g) }\end{array}$} & \multirow[b]{2}{*}{$\begin{array}{c}\text { Average } \\
\text { gestational } \\
\text { age (wk) }\end{array}$} & \multirow{2}{*}{$\begin{array}{c}\text { Average } \\
\text { maternal } \\
\text { age } \\
\text { (Y) }\end{array}$} & \multirow{2}{*}{$\begin{array}{c}\% \text { of } \\
\text { mothers } \\
\text { who are } \\
\text { Caucasian }\end{array}$} & \multicolumn{2}{|c|}{ Twin factors } & \multicolumn{3}{|c|}{$\begin{array}{l}\text { Mortality/morbidity } \\
\text { singletons }\end{array}$} & \multicolumn{3}{|c|}{ Mortality/morbidity twins } \\
\hline & & & & & & & $\begin{array}{c}\text { Proportion } \\
(\%)\end{array}$ & $\begin{array}{c}\text { Same- } \\
\text { sex } \\
(\%)\end{array}$ & $\begin{array}{l}\text { Still- } \\
\text { birth } \\
(\%)\end{array}$ & $\begin{array}{c}\text { Neonatal } \\
(\%)\end{array}$ & $\begin{array}{c}\text { Cerebral } \\
\text { palsy } \\
(\%)\end{array}$ & $\begin{array}{l}\text { Still- } \\
\text { birth } \\
(\%)\end{array}$ & $\begin{array}{c}\text { Neonatal } \\
(\%)\end{array}$ & $\begin{array}{c}\text { Cerebral } \\
\text { palsy } \\
(\%)\end{array}$ \\
\hline W Aust & 232316 & $1980-89$ & 3343 & 39.1 & 26.8 & 89.8 & 2.3 & 70.5 & 0.72 & 0.46 & 0.20 & 2.94 & 3.64 & 0.82 \\
\hline Victoria & 430212 & $1983-89$ & 3363 & 39.2 & 27.7 & NA & 2.3 & 70.8 & 0.64 & 0.42 & 0.09 & 2.61 & 2.68 & 0.31 \\
\hline S Aust & 58609 & $1986-88$ & 3351 & 39.2 & 27.1 & 95.1 & 2.5 & 71.2 & 0.61 & 0.40 & NA & 2.07 & 2.11 & 0.95 \\
\hline Calif & 149509 & $1983-85$ & 3370 & 39.7 & 27.2 & 73.1 & 2.0 & 75.1 & 0.49 & 0.40 & 0.11 & 1.88 & 2.99 & 0.70 \\
\hline Georgia & 270705 & $1981-89$ & 3291 & 39.0 & 26.3 & 62.4 & 2.3 & 70.4 & 0.75 & 0.63 & 0.19 & 3.02 & 4.26 & 0.73 \\
\hline Total & 1141351 & & 3342 & 39.2 & 27.1 & 76.4 & 2.3 & 71.2 & 0.66 & 0.48 & 0.14 & 2.66 & 3.25 & 0.59 \\
\hline
\end{tabular}

CRUDE MORTALITY RATE (STILL-BIRTH) - \% of all births (stillbirths and live births) that were stillbirths.

CRUDE MORTALITY RATE (NEONATAL) - \% of live born infants who died within 28 days of birth.

CRUDE CEREBRAL PALSY RATE - \% of all infants alive at 1 year who have Cerebral Palsy (South Australia has CP data only for twins).

TWINS-PROPORTION - \% of all births that were twins.

TWINS-SAME-SEX - \% of matched twins who are the same sex as their co-twin.

Australia: 2.6\% Asian, 1.8\% Aboriginal; California†: 10.9\% Asian, $7.9 \%$ Black; Georgia; 36.8\% Black. Maternal race was not available in the Victorian data set.

Secular trends. The proportion of births that were twins or higher-order multiples, increased from 1.9 in 1980 to $2.5 \%$ in $1989 .+$ Of three major factors associated with twinning, race, maternal age, and use of assisted reproductive therapy, it was possible to assess only the influence of maternal age, which increased slightly from 26.1 to $27.7 \mathrm{y}$ over this time period. The proportion of mothers aged $35 \mathrm{y}$ or more increased from 5.9 to $9.9 \%$ of all births. Compatible with increasing maternal age and increased use of assisted reproductive therapy, different-sex pairs increased from $24 \%$ to $32 \%$ of all twin pairs. All of these linear trends were statistically significant $(p<0.05)$ for the combined dataset. These trends were also generally apparent for each of the five study populations, although not always to a statistically significant degree.

Characteristics of twin pregnancies. Twins or higher order multiples represented $2.3 \%$ of all births, $1.2 \%$ of all pregnancies. The prevalence of twin pair types was as follows: male-only pairs (36\%), female-only pairs $(35 \%)$, mixed pairs $(29 \%)$. Since it is assumed that the mixed pairs represent half of the dizygotic pairs, 58\% (2 times 29\%) of the twins are estimated to be dizygotic and, by subtraction, $42 \%$ are monozygotic pairs. Thus $29 / 71=40.8 \%$ of the like sex pairs are dizygotic.

The average gestational age for twin pregnancies was about 3 wk less than for singleton pregnancies (Fig. 1A). $\S$ In 16\% of (live born) twins, the absolute weight difference between the infants exceeded $20 \%$ of the larger twin's birth weight. Size discordance was more common in different-sex than in samesex pairs $(18.2 \%$ versus $14.9 \%, p<0.001)$ (including only pairs in which both infants were live-born).

Characteristics of twins. On average, live-born twins were about $940 \mathrm{~g}$ smaller than live-born singletons (Fig.

$\dagger$ Caucasian includes those entered as White/non-Hispanic and White/Hispanic.

$\$$ Values shown for these characteristics in 1980 and 1989 were derived from predicted values based on linear or Poisson regression.
1B). $\S$ While only $5 \%$ of (live born) singletons weighed less than $2500 \mathrm{~g}$ at birth, $48 \%$ of twins weighed less than $2500 \mathrm{~g}$. Similarly, only $1 \%$ of singletons but $8 \%$ of twins weighed less than $1500 \mathrm{~g}$.

The weight difference between singletons and twins was apparent at all gestational ages: The higher median birth weight in singletons increased from $70 \mathrm{~g}$ at $24 \mathrm{wk}$ to $590 \mathrm{~g}$ at $40 \mathrm{wk}$. Among twins, second-born live-born twins were smaller than first-born live-born twins by $43 \mathrm{~g} \S$ and same-sex twins were smaller than different-sex twins by $74 \mathrm{~g}$. Female twins who had a female-co-twin were about $62 \mathrm{~g}$ smaller than female twins who had a male co-twin. Male twins who had a male co-twin were about $86 \mathrm{~g}$ smaller than male twins who had a female co-twin.

Rates of early mortality and CP are shown by demographic factors for singletons and twins in Table 2 and by twin factors in Table 3, presented first for early mortality and then for CP.

\section{Mortality Rates in Singletons and Twins}

Demographic factors. Overall, twins had approximately five times greater risk of stillbirth or neonatal death than singletons (Table 2). Singletons were at higher risk of stillbirth $(0.66 \%$ $[0.64 \%-0.68 \%]$ of all births) than neonatal mortality $(0.47 \%$ [0.46\%- $0.48 \%]$ of all births), whereas twins were at higher risk of neonatal mortality $(3.17 \%$ [2.90\%-3.44\%] of all births) than stillbirth (2.66\% [2.42\%-2.90\%] of all births).

Crude rates of mortality were higher for males and for nonwhites for both singletons and twins. Nonwhites were on average smaller and less mature at birth than whites. To compare mortality rates among whites and nonwhites (and other groups with different average birth weights and gestational ages), logistic regression was used to calculate odds ratios adjusted for birth weight and gestational age (see methods). After adjustment, nonwhites had lower risk of mortality (OR $=0.81$ singletons, $\mathrm{OR}=0.61$ twins, $p<0.0001)$ than whites. Similarly, singletons of both younger $(<20 \mathrm{y})$ and older ( $\geq 35 \mathrm{y}$ ) mothers were at increased risk of early death.

$\S$ All comparisons t-test or chi-square with cluster sampling, $p<0.0001$. 

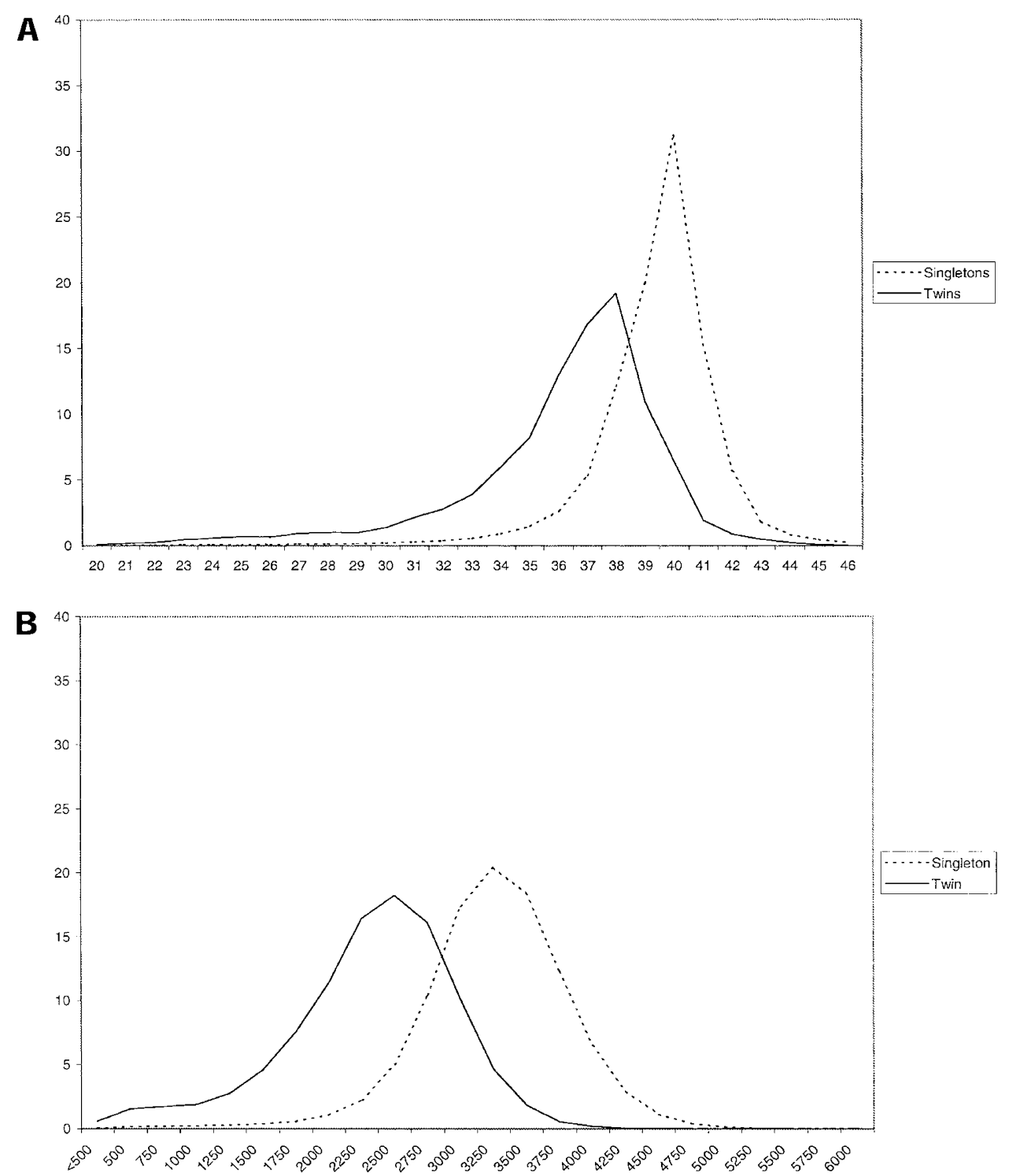

Figure 1. $(A, B)$ Gestational age and birth weight distribution for live-born singletons and twins.

After adjustment for birth weight and gestational age, singletons of younger mothers were at reduced risk of mortality (OR $=0.89, p=0.002$ ), while singletons of older mothers remained at increased risk $(\mathrm{OR}=1.20, p<0.0001)$. A similar pattern was seen for twins as for singletons after adjustment, i.e. rates were lower for twins of younger mothers and increased for twins of older mothers, but was not statistically significant.

Twin factors. While the overall rate of early mortality was higher in twins than singletons, the pattern of risk varied by birth weight and gestational age strata. Figure 2 shows the rate of mortality by birth weight and gestational age for singletons and twins. Very low birth weight twins and singletons had similar rates of mortality (Fig. 2). Above $1000 \mathrm{~g}$ but less than $2750 \mathrm{~g}$, twins had a lower rate of mortality. Above that weight, twins had similar or higher mortality rates. When viewed by gestational age, twins had higher mortality rates below about 27 wk gestational age, lower rates from about 30 to $35 \mathrm{wk}$ gestational age, and higher rates above 38 wk gestational age.
Overall, singletons in the $3250-4500 \mathrm{~g}$ weight range or at $40-41 \mathrm{wk}$ gestational age had the greatest chance of surviving the neonatal period (visible on a log scale - Fig. 2 C, D). For twins, the corresponding optimal birth weight and gestational age was $2500-3750 \mathrm{~g}$ and 37-38 wk gestational age. Even at optimal birth weight, however, twins had approximately twice the risk of early mortality compared with singletons at optimal birth weight $(0.43 \%$ versus $0.20 \%$ approximately).

Table 3 shows mortality rates for twins by twin-specific factors, including birth order, twin type, gender-pair type, growth discordance, and co-twin outcome. To include both twins in each pair, twins with missing or out of range gestational age are included in these rates. Rates of mortality were increased for second-born twins and twins in same-sex pairs, and especially for male-only pairs. Adjustment for birth weight and gestational age did not change these patterns.

Mortality rates were greatly increased for twins whose cotwin had died in the neonatal period compared with twins whose co-twin survived the neonatal period. This increased 
Table 2. Crude early mortality (still-birth or neonatal) and crude cerebral palsy (CP) rates in singletons and twins by demographic

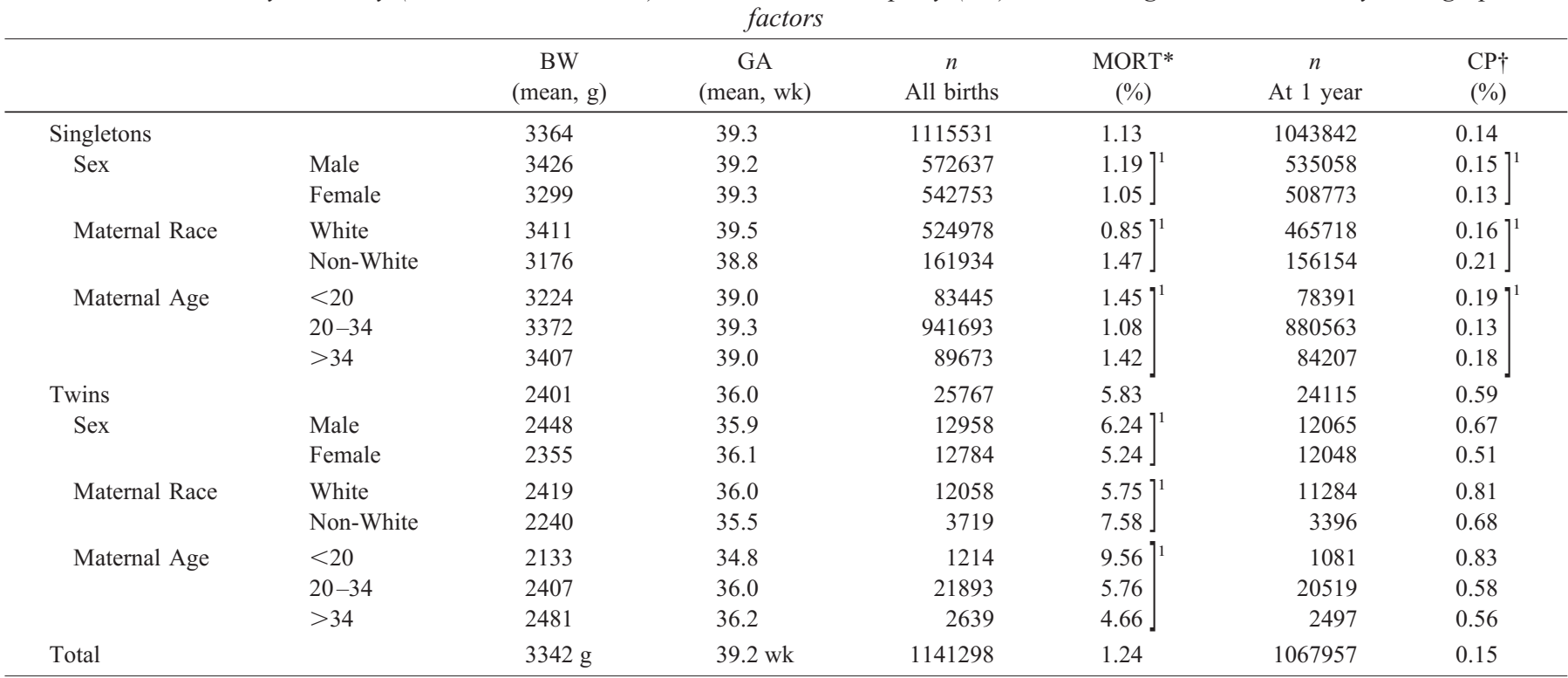

Note: Excludes infants births with unknown birth weight or unknown/out of range gestational age.

* Mortality rates expressed as a percentage of all births. Mortality includes stillbirth and neonatal mortality and "all births" includes live births and stillbirths.

$\dagger$ Cerebral palsy rates expressed as a percentage of all infants alive at 1 year.

${ }^{1} p<0.005 \chi^{2}$ ( $p$-values calculated taking into account non-independence of twin data).

risk was apparent across the birth weight range (Fig. 3A) but appears largely confined to same-sex twins (Fig. 3B). Overall, the risk of mortality in twins whose co-twin was a neonatal survivor was $2.2 \%$, was $64 \%$ for different-sex twins whose co-twin died, and was $73 \%$ for same-sex twins whose co-twin died. This difference in risk persisted after adjustment for gestational age and birth weight: compared with twins whose co-twin was a neonatal survivor, same-sex twins whose cotwin died had higher risk of death $(\mathrm{OR}=15.2[10.7-21.6], p<$ $0.0001)$ than different-sex twins whose co-twin died (OR $=$ $3.6[2.0-6.7], p<0.001)$.

Rates of mortality are also shown for growth discordant twins and are based on twins in pairs in which both twins were live-born (Table 3). Mortality was increased for both twins in

Table 3. Crude early mortality (still-birth and neonatal), and crude cerebral palsy (CP) rates by twin factors

\begin{tabular}{|c|c|c|c|c|c|c|c|}
\hline & & $\begin{array}{c}\text { BW } \\
\text { (mean, g) }\end{array}$ & $\begin{array}{c}\mathrm{GA}^{*} \\
\text { (mean, wk) }\end{array}$ & $\begin{array}{c}n \\
\text { All Births }\end{array}$ & $\begin{array}{l}\text { MORT } \\
(\%)\end{array}$ & $\begin{array}{c}n \\
(1 \\
\text { Year) }\end{array}$ & $\begin{array}{l}\text { CP } \\
(\%)\end{array}$ \\
\hline Birth order & $\begin{array}{l}1^{\text {st }} \\
2^{\text {nd }}\end{array}$ & $\begin{array}{l}2408 \\
2362\end{array}$ & $\begin{array}{l}35.9 \\
35.9\end{array}$ & $\begin{array}{l}13235 \\
13274\end{array}$ & $\left.\begin{array}{l}6.38 \\
7.40\end{array}\right]^{1}$ & $\begin{array}{l}12327 \\
12197\end{array}$ & $\begin{array}{l}0.56 \\
0.61\end{array}$ \\
\hline Twin type & $\begin{array}{l}\text { Same-sex } \\
\text { Different-sex }\end{array}$ & $\begin{array}{l}2363 \\
2453\end{array}$ & $\begin{array}{l}35.9 \\
36.1\end{array}$ & $\begin{array}{r}18799 \\
7620\end{array}$ & $\left.\begin{array}{l}7.11 \\
4.92\end{array}\right]^{1}$ & $\begin{array}{r}17344 \\
7203\end{array}$ & $\begin{array}{l}0.59 \\
0.56\end{array}$ \\
\hline Pair type $\dagger$ & $\begin{array}{l}\text { M:M } \\
\text { M:F } \\
F: M \\
F: F\end{array}$ & $\begin{array}{l}2400 \\
2510 \\
2395 \\
2324\end{array}$ & $\begin{array}{l}35.8 \\
36.1 \\
36.1 \\
36.0\end{array}$ & $\begin{array}{l}9536 \\
3810 \\
3810 \\
9263\end{array}$ & $\left.\begin{array}{l}7.91 \\
4.93 \\
4.91 \\
6.29\end{array}\right]^{1}$ & $\begin{array}{l}8710 \\
3604 \\
3599 \\
8634\end{array}$ & $\begin{array}{l}0.65 \\
0.64 \\
0.47 \\
0.52\end{array}$ \\
\hline $\begin{array}{l}\text { Growth } \\
\text { Discordance }\end{array}$ & $\begin{array}{l}\text { No } \\
\text { Yes } \$ \\
\text { Smaller§ } \\
\text { Larger** }\end{array}$ & $\begin{array}{l}2471 \\
2269 \\
1904 \\
2634\end{array}$ & $\begin{array}{l}36.3 \\
35.9 \\
35.9 \\
35.9\end{array}$ & $\begin{array}{r}21210 \\
4000 \\
2000 \\
2000\end{array}$ & $\left.\left.\begin{array}{l}2.81 \\
5.03\end{array}\right]^{6.00}\right]\left.\left.^{1}\right|^{1}\right|^{1}$ & $\begin{array}{r}20494 \\
3769 \\
1854 \\
1915\end{array}$ & 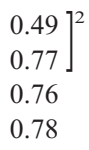 \\
\hline
\end{tabular}

Note: All births, including those with unknown birth weight or unknown/out of range gestational age.

* For this column only, based on infants with valid (20-46) gestational age.

$\dagger \mathrm{M}: \mathrm{M}$, male twins from same-sex pairs; M:F, male twins from mixed pairs; F:F, female twins from same-sex pairs; F:M, female twins from mixed pairs.

$\$$ Twins from pairs in which the difference in birth weight exceeds $20 \%$ of the larger twin's birth weight. This comparison limited to twin pairs in which both twins were live-born.

$\S$ Comparing the smaller twin in a discordant pair with twins from non-discordant pairs.

** Comparing the larger twin in a discordant pair with twins from non-discordant pairs.

${ }^{1} p<0.005, \chi^{2}$ ( $p$-values calculated taking into account non-independence of twin data).

${ }^{2} p<0.05, \chi^{2}$ ( $p$-values calculated taking into account non-independence of twin data). 

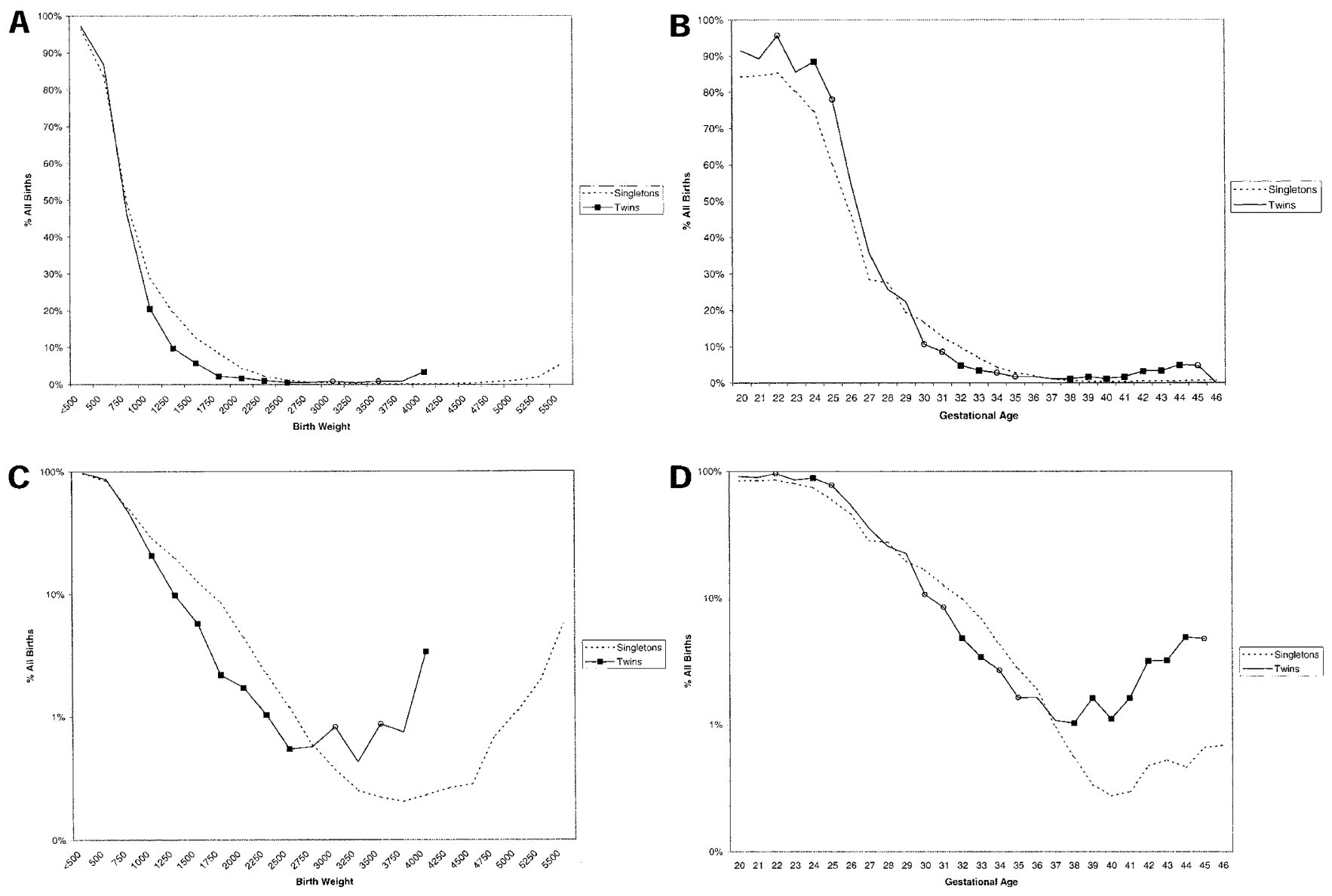

Figure 2. $(A, B)$ Mortality (still-birth and neonatal) by birth weight and gestational age for singletons and twins. $\square<0.002$, difference between singletons and twins. $\circ p<0.05$, difference between singletons and twins. Note Birth weight is combined above 4000 grams for twins and above 5500 grams for singletons. $(C, D)$ Log scale.

the pair, but increased more in the smaller twin $(p=0.005)$. Not shown in this table, a similar pattern was seen when all twin pairs, including those with a stillborn co-twin, were included.

\section{Rates of Cerebral Palsy in 1-Year Survivors}

Demographic factors. Trends suggested that the crude rates of CP varied by demographic factors in ways mostly similar to the crude rates of fetal and neonatal mortality. These associations did not always reach the level of statistical significance in the smaller twins cohort (Table 2). The crude rate of $\mathrm{CP}$ was higher for male infants, nonwhite singleton (but not twin) infants, singletons of both younger and older mothers, and twins of younger mothers (Table 2). Similar to mortality rates, rates of $\mathrm{CP}$ adjusted for birth weight and gestational age were lower in nonwhite infants for singletons (OR $=0.83, p=$ $0.007)$ and twins (OR $=0.60, p=0.037)$. Singletons born to older mothers were at higher risk of $\mathrm{CP}$ after adjustment (OR $=1.24, p=0.014)$, however twins born to older mothers were not at increased risk (OR $=1.06, p=0.84)$.

Twin factors. Overall, CP was approximately four times as common in twin 1-y survivors than singleton 1-y survivors (Table 2: $0.59 \%$ versus $0.14 \%, p<0.0001$ ). Twins appeared to be at increased risk relative to singletons above about $38 \mathrm{wk}$ or
2500 g (Fig. 4). The pattern for less mature infants was less clear. It should be noted that because mortality is so high in the 20-23 week gestational age range, most of the 1-y survivors in this gestational age range probably had an incorrect gestational age - particularly so for singletons. For example, at $20 \mathrm{wk}$ gestational age, the average birth weight for the 1-y surviving singletons was an implausibly high $2294 \mathrm{~g}$. The corresponding birth weight for surviving twins was $1163 \mathrm{~g}$.

Crude and adjusted rates of $\mathrm{CP}$ were similar for first and second-born twins and same-sex and different-sex twins (Table 3). Rates of CP are shown for twins from growth discordant pairs in which both twins were live-born. In these pairs, surviving growth discordant twins are at increased crude risk of $\mathrm{CP}$ and the risk was similar for the smaller and larger twin. After adjustment for birth weight and gestational age in separate logistic models for the smaller twin and larger twin, there was no increased risk of $\mathrm{CP}$ for the smaller twin in a discordant pair $(\mathrm{OR}=0.63[0.35-1.15])$ or for the larger twin in a discordant pair $(\mathrm{OR}=1.65,[0.95-2.88])$ compared with twins from nondiscordant pairs.

Crude rates of $\mathrm{CP}$ were much higher in twins whose co-twin died compared with those whose co-twin survived the neonatal period $(5.4 \%$ versus $0.48 \%, p<0.0001)$. This rate was similar for same-sex $(5.7 \%)$ and different-sex twins $(5.3 \%)$ and for 
A

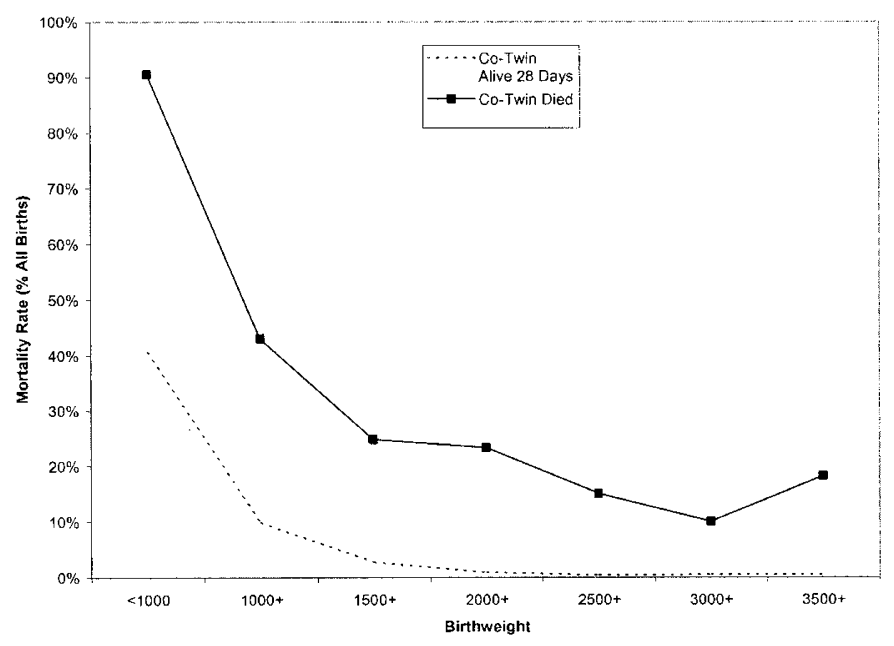

B

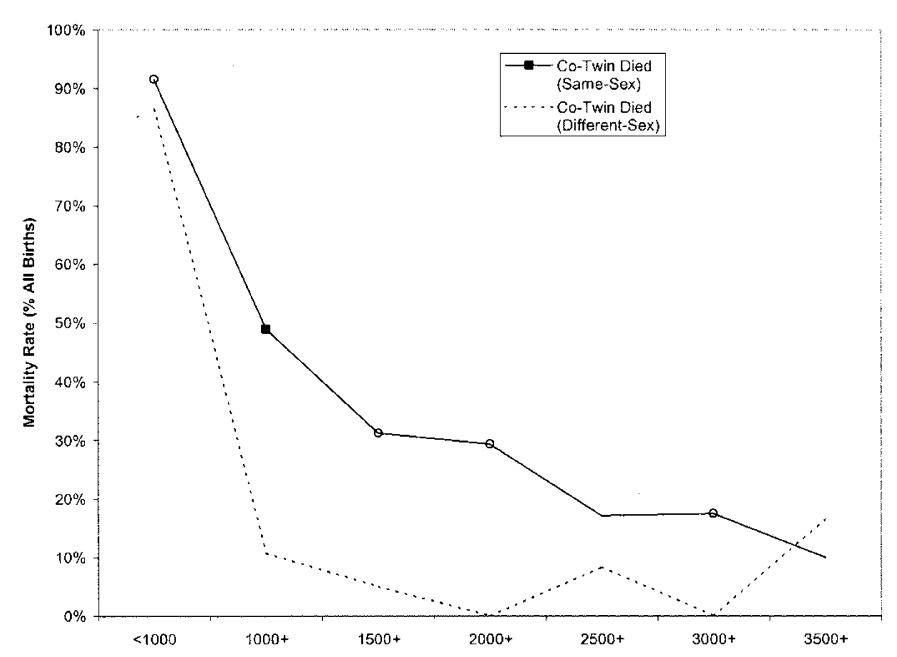

Figure 3. (A) Mortality by birth weight and co-twin mortality. $\quad p<0.004$, difference between twins whose co-twin was a neonatal survivor and twins whose co-twin was not a neonatal survivor. $(B)$ Mortality by birth weight and pair type (same-sex vs different-sex) for twins whose co-twin died. $\square p<0.004$, difference between twins from same-sex pairs whose co-twin died and twins from different-sex twin pairs whose co-twin died. $\bigcirc P<0.05$, difference between twins from same-sex pairs whose co-twin died and twins from different-sex twin pairs whose co-twin died.

twins whose co-twin was stillborn (4.7\%) versus twins whose co-twin died in the neonatal period $(6.3 \%)$. The highest rate of CP (11.8\%) was in twins whose co-twin had CP (latter data not shown).

The increase in risk of $\mathrm{CP}$ following co-twins death was apparent across the range of birth weight (Fig. 5A), but unlike the pattern seen for mortality, the excess risk of $\mathrm{CP}$ in surviving twins whose co-twin died was not obviously different for same-sex versus different-sex twins by birth weight strata (Fig. 5B). Compared with 1-y survivors whose co-twin survived, the adjusted odds of $\mathrm{CP}$ for twins whose co-twin died was 3.8 [2.3-6.4]. By twin type, the adjusted OR was 4.3 [2.2-8.4] for same-sex twins and 2.4 [1.0-5.8] for different-sex twins, not a statistically significant difference.

\section{DISCUSSION}

In agreement with well-documented trends in the United States, Australia, and elsewhere $(2,3)$, we found increases in births to older mothers and overall rates of twinning. The increasing prevalence of multiple births has become even more obvious in recent years, partly attributable to delayed childbearing but primarily fueled by the increased use of assisted reproductive techniques. Also consistent with other reports (20, 21 ), we found that early mortality rates (still birth and neonatal) were lower for nonwhites than whites after adjustment for birth weight and gestational age. This pattern was also observed for adjusted rates of $\mathrm{CP}$ in both nonwhite twin and singleton infants. 


\section{A}

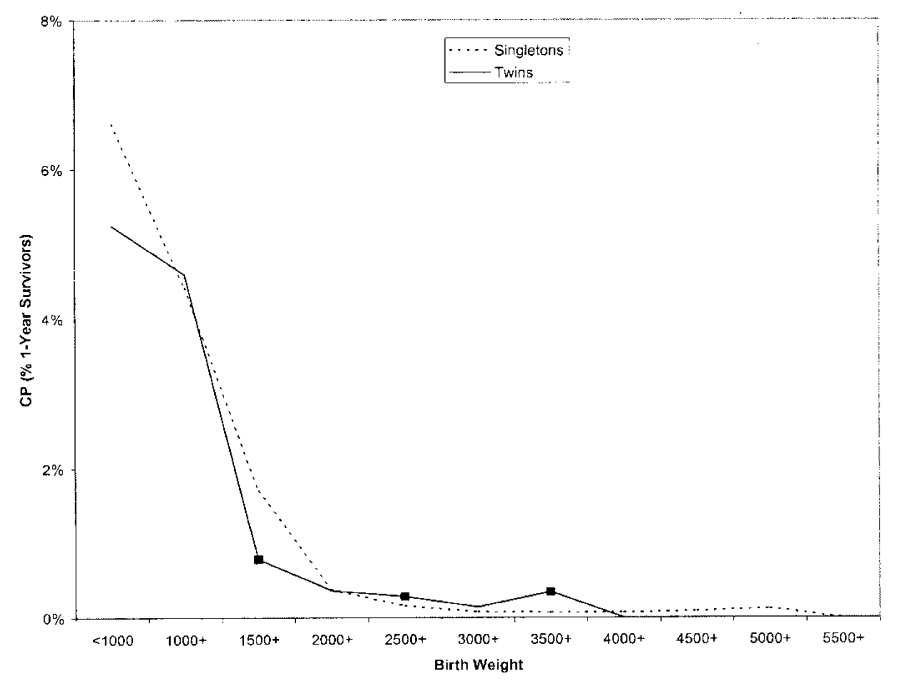

$\mathbf{B}$

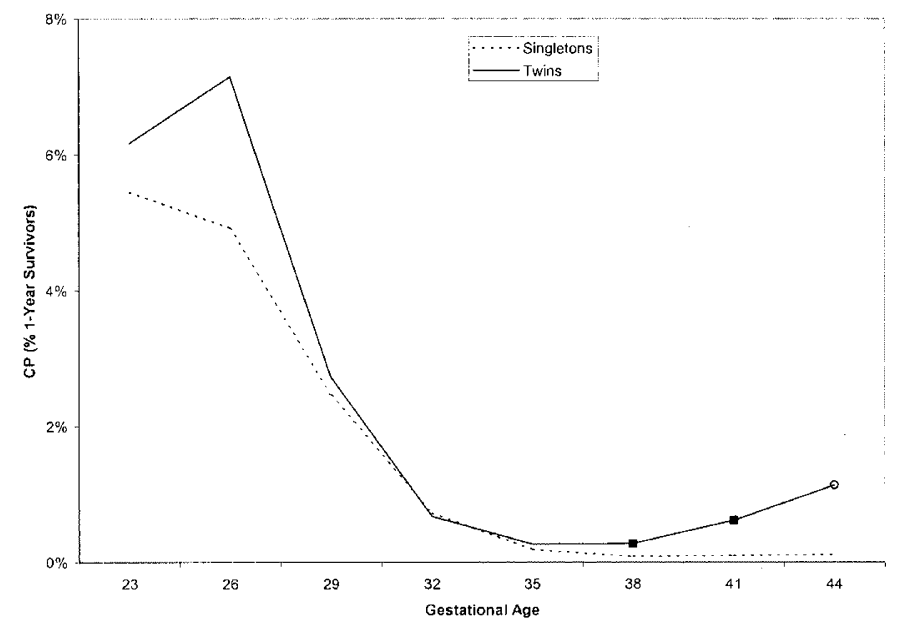

Figure 4. $(A, B)$ Cerebral palsy by birth weight and gestational age for singletons and twins. $\square p<0.004$, difference between singletons and twins. $\circ p<0.05$, difference between singletons and twins.

Overall, twins had a greater risk of early death or cerebral palsy compared with singletons. Singletons were at higher risk of stillbirth than neonatal mortality while twins were at higher risk of neonatal mortality than stillbirth, because very small twins $(<1000 \mathrm{~g})$ more often survived birth than very small singletons but were then more likely to die in the neonatal period. The greater frequency of caesarean sections in twins than singletons may play a role in this difference, as lower rates of stillbirth were seen for both singletons and twins delivered via caesarean section, and twins were more often delivered this way.

The risk of death in twins, which was lower than in singleton infants below $2500 \mathrm{~g}$, increased relative to singletons with increasing birth weight or gestational age (Fig. 2). It was at more mature gestational ages that threat of mortality in twins exceeded that in singleton infants, in agreement with results reported elsewhere $(4,8,22-24)$. However, even at the most favorable birth weight, twins still had approximately twice the risk of early mortality or $\mathrm{CP}$ than singletons at their optimal birth weight. Furthermore, the divergent growth patterns of singletons and twins were evident as early as $20 \mathrm{wk}$ gestational age, in accordance with other reports (25).

Twins from growth discordant pairs were at increased risk of both early mortality and of CP. Twin-twin transfusion syndrome (TTTS), an important cause of growth discordance, occurs in about $15 \%$ to $35 \%$ of monochorionic twins (26-28) and been estimated to account for $5 \%$ to $20 \%$ of perinatal mortality in twins (28). Some case series have reported higher morbidity in the heavier preterm (29) but not term (30) twin. Size discordancy is often, but not always, found in TTTS (27). Furthermore, half or fewer of monochorionic twins who are growth discordant have TTTS (27). Other conditions that may cause size discordancy in twins include genetic differences, antenatal infection, and uteroplacental insufficiency (27). Size discordancy is thus a highly imperfect measure of TTTS.

The risk of death of a twin was greater if the co-twin died in utero or shortly after birth. While observed across the whole 


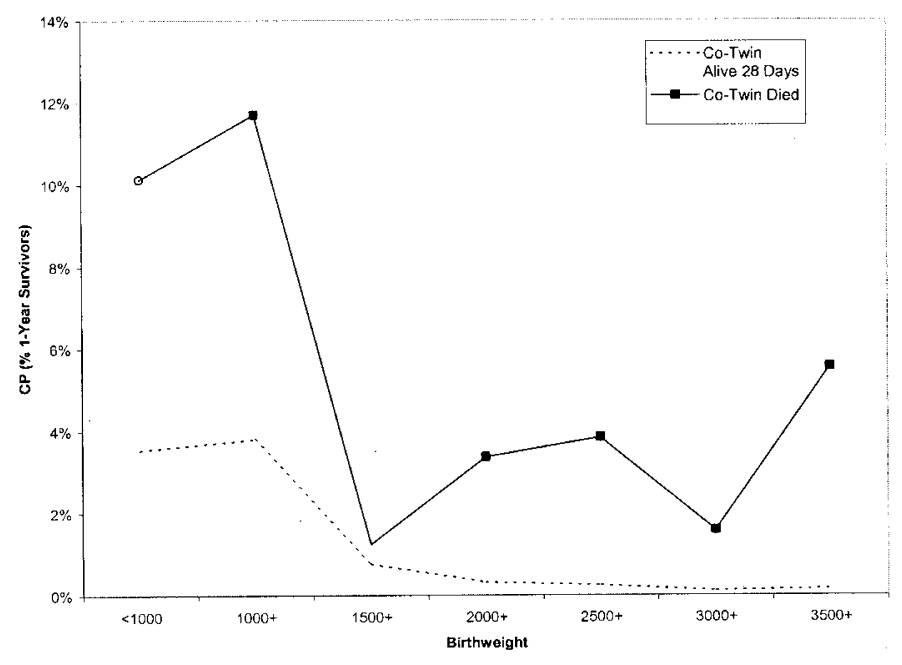

B

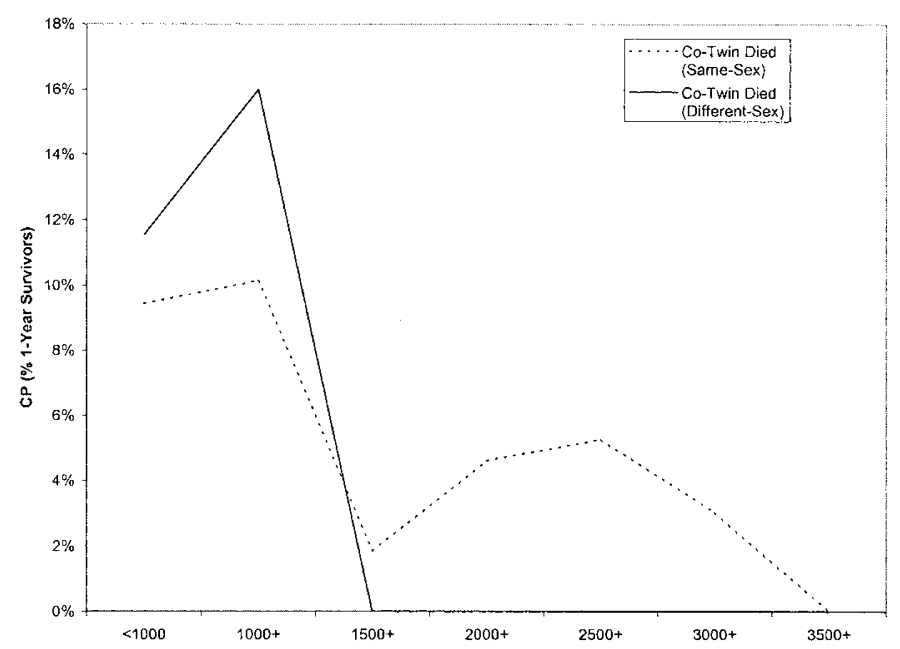

Figure 5. (A) Cerebral palsy by birth weight and co-twin mortality. $p<0.002$, difference between infants whose co-twin was a neonatal survivor and infants whose co-twin was not a neonatal survivor. $\circ p<0.05$, difference between infants whose co-twin was a neonatal survivor and infants whose co-twin was not a neonatal survivor. $(B)$ Cerebral palsy by birth weight and pair type (same-sex vs different-sex) for twins whose co-twin died.

range of birth weight, the relative increase in risk was greatest among the largest infants due to the low risk of neonatal death in term infants (Fig. 3). Same-sex twin pairs were at greater risk than different-sex twin pairs following the death of a co-twin; this difference was statistically significant only for smaller twins, due to the relatively low mortality of larger infants.

If one twin died, the risk of $\mathrm{CP}$ in the survivor was at least 10 -fold greater than if the co-twin survived. Death of a co-twin was thus a powerful predictor of $\mathrm{CP}$ in twins. Because failure to record a fetal death, especially one occurring early in a multiple gestation, is an inherent problem in vital records, there is probably under ascertainment of multiple gestations complicated by fetal death. The possible contribution of the often undocumented "vanishing twin" to neurologic morbidity in the survivor, who is often registered as a singleton birth, has been a subject of speculation (31). Presumably this would underes- timate the contribution of co-twin death to childhood neurologic morbidity (32).

The higher risk of CP in the child whose co-twin died was apparent over the birth weight range examined (Fig. 5). While the excess risk of mortality associated with the death of a co-twin was more pronounced in same-sex than in different-sex twin pairs, this was not the case for CP, perhaps because of the higher rate of death in same-sex pairs presented a competing risk. One other report based on a large population-based registry found the risk of $\mathrm{CP}$ in a twin whose co-twin died in utero to be considerably higher in same-sex pairs $(10.6 \%)$ than in different-sex pairs $(2.9 \%)$ (33). As the authors of this report pointed out, an anomaly in the way the sex of infants who died in utero was registered requires cautious interpretation of this result. Similar, but nonsignificant results, were reported for rates of CP following the neonatal death of the co-twin in the same 
population (34) and for rates of $\mathrm{CP}$ following fetal or neonatal death of the co-twin in a different population (35).

A number of other investigators have stressed the relatively high risk of cerebral impairment in the surviving child whose co-twin died in utero $(4-6,36-38)$. The mechanism by which brain injury occurs in a twin whose co-twin died in utero is usually discussed with reference to placental anastomoses or to cord entanglement, and thus considered to be a feature of monozygotic twin pregnancies. The neuropathologic findings in such cases include massive destructive lesions that might be consequences of drastic vascular disruption, with multicystic encephalomalacia, hydranencephaly, and porencephaly. Such vascular events earlier in gestation might produce microgyria and heterotopias. Along with the cerebral lesions, consequences of vascular events in other organs systems - gastrointestinal, urogenital, and other - may be observed. Other routes to adverse outcome in both members of a twin pair also need consideration: MZ twins more often than DZ or singletons infants have malformations or chromosomal aberrations. Noxious events (i.e. coagulation disorders) that kill one twin can sub lethally injure the other, a general mechanism that can involve dizygotic as well as monozygotic pairs. It has not been demonstrated that medical intervention after one twin has died can prevent cerebral catastrophe in the other $(39,40)$.

This is the largest population-based study of CP to date, affording an opportunity to consider multiple factors possibly associated with this disorder. Inevitably, the statistical power and representativeness afforded by this large sample size comes with the tradeoff that clinical information is less ample and detailed than is possible in smaller clinical studies from referral centers. Two examples of the limitations are zygosity and gestational age: we were limited to using twin-pair gender type as a proxy since information on zygosity was not available. Since approximately $40 \%$ of same sex pairs are dizygotic, any risk associated with monozygosity was necessarily diluted. Gestational age as reported in vital records has known limitations (41) and because information was restricted to infants of at least $20 \mathrm{wk}$ gestational age, we were not able to examine risks to a twin following the early fetal death of a co-twin. Furthermore, the populations studied differed in terms of racial composition, medical care, and rates of $\mathrm{CP}$. However, our combined prevalence rates for $\mathrm{CP}$ in the five populations surveyed were within the range of other population-based studies using varying case and population definitions $(4-6,23$, $42-58)$.

\section{CONCLUSION}

Although twins were at increased risk of early death or CP relative to singletons, small twins generally fared better than small singletons. Co-twin death was a strong predictor of $\mathrm{CP}$ in surviving twins. This risk was the same for same- and different-sex pairs, and observed across the birth weight spectrum.

Acknowledgments. As this was a multi-center study, there were numerous individuals involved in a meaningful way at each of the participating study sites. In particular, we would like to acknowledge the contributions of the following people:
Annabelle Chan, Susan Beal, Peter Flett, Rosemary ByronScott (South Australia); Fiona Stanley, Linda Watson, Helen Galea (West Australia); G. Dite (Victoria); Coleen Boyle, Tanya Karapurkar, Catherine Murphy (Atlanta); Jenny Hoogstrate (California).

\section{REFERENCES}

1. Luke B 1994 The changing pattern of multiple births in the United States: maternal and infant characteristics, 1973 and 1990. Obstet Gynecol 84:101-106

2. Martin JA, Park MM 1999 Trends in twin and triplet births: 1980-97. National vital statistics reports, vol 47(24):1-17. Hyattsville, MD, National Center for Health Statistics.

3. Imaizumi Y 1997 Trends of twinning rates in ten countries, 1972-1996. Acta Genet Med Gemellol (Roma) 46:209-218

4. Nelson KB, Ellenberg JH 1995 Childhood neurological disorders in twins. Paediatr Perinat Epidemiol 9:135-145

5. Williams K, Hennessy E, Alberman E 1996 Cerebral palsy: effects of twinning, birthweight, and gestational age. Arch Dis Child Fetal Neonatal Ed 75:F178-F182

6. Pharoah PO, Cooke T 1996 Cerebral palsy and multiple births. Arch Dis Child Fetal Neonatal Ed 75:F174-F177

7. Yokoyama Y, Shimizu T, Hayakawa K 1995 Prevalence of cerebral palsy in twins, triplets and quadruplets. Int J Epidemiol 24:943-948

8. McCarthy BJ, Sachs BP, Layde PM, Burton A, Terry JS, Rochat R 1981 The epidemiology of neonatal death in twins. Am J Obstet Gynecol 141:252-256

9. Kleinman JC, Fowler MG, Kessel SS 1991 Comparison of infant mortality among twins and singletons: United States 1960 and 1983. Am J Epidemiol 133:133-143

10. Powers WF, Wampler NS 1996 Further defining the risks confronting twins. Am J Obstet Gynecol 175:1522-1528

11. Stanley FJ, Croft ML, Gibbins J, Read AW 1994 A population database for maternal and child health research in Western Australia using record linkage. Paediatr Perinat Epidemiol 8:433-447

12. Beischer NA 1990 The Consultative Council on Obstetric and Paediatric Mortality and Morbidity Annual Report for the Year 1990: Incorporating the 29th Survey of Perinatal Deaths in Victoria. 4-13: Melbourne, Vic., Department of Human Services, Public Health Division

13. Chan A, Macharper T, Lister J 1986 Pregnancy outcome in South Australia 1986. 1. Adelaide, Pregnancy Outcome Unit, Epidemiology Branch, South Australia Health Commission

14. Byron-Scott R, Chan A, Scott H, and Haan E 1997 Annual Report of the South Australian Birth Defects Register. 32. 1999. Women's and Children's Hospital, North Adelaide, South Australia

15. Grether JK, Cummins SK, Nelson KB 1992 The California Cerebral Palsy Project. Paediatr Perinat Epidemiol 6:339-351

16. Boyle CA, Yeargin-Allsopp M, Doernberg NS, Holmgreen P, Murphy CC, Schendel DE 1996 Prevalence of selected developmental disabilities in children 3-10 years of age: the Metropolitan Atlanta Developmental Disabilities Surveillance Program, 1991. Mor Mortal Wkly Rep CDC Surveill Summ 45:1-14

17. Adams MM, Wilson HG, Casto DL, Berg CJ, McDermott JM, Gaudino JA, McCarthy BJ 1997 Constructing reproductive histories by linking vital records. Am J Epidemiol 145:339-348

18. Adams MM, Berg CJ, McDermott JM, Gaudino JA, Casto DL, Wilson HG, McCarthy BJ 1997 Evaluation of reproductive histories constructed by linking vital records. Paediatr Perinat Epidemiol 11:78-92

19. Stata Version 6.0. Stata Corporation, College Station, Texas

20. Mittendorf R, Williams MA, Kennedy JL, Berry RE, Herschel M, Aronson MP, Davidson KM 1993 A hypothesis to explain paradoxical racial differences in neonatal mortality. Am J Prev Med 9:327-330

21. Fowler MG, Kleinman JC, Kiely JL, Kessel SS 1991 Double jeopardy: twin infant mortality in the United States, 1983 and 1984. Am J Obstet Gynecol 165:15-22

22. Minakami H, Sato I 1999 Birth-weight-specific perinatal mortality in japan, 19891993: singleton versus multifetal pregnancies. Gynecol Obstet Invest 48:38-42

23. Liu J, Li Z, Lin Q, Zhao P, Zhao F, Hong S, Li S 2000 Cerebral palsy and multiple births in China. Int J Epidemiol 29:292-299

24. Kiely JL 1990 The epidemiology of perinatal mortality in multiple births. Bull N Y Acad Med 66:618-637

25. Alexander GR, Kogan M, Martin J, Papiernik E 1998 What are the fetal growth patterns of singletons, twins, and triplets in the United States? Clin Obstet Gynecol 41:114-125

26. Minakami H, Honma Y, Matsubara S, Uchida A, Shiraishi H, Sato I 1999 Effects of placental chorionicity on outcome in twin pregnancies. A cohort study. J Reprod Med 44:595-600

27. Wenstrom KD, Tessen JA, Zlatnik FJ, Sipes SL 1992 Frequency, distribution, and theoretical mechanisms of hematologic and weight discordance in monochorionic twins. Obstet Gynecol 80:257-261

28. Filkins KA, Beverly SE 1998 Twin-twin transfusion syndrome: the challenge of etiology-based management decisions. Curr Opin Obstet Gynecol 10:441-446

29. Sonntag J, Waltz S, Schollmeyer T, Schuppler U, Schroder H, Weisner D 1996 Morbidity and mortality of discordant twins up to 34 weeks of gestational age. Eur J Pediatr 155:224-229

30. Blickstein I, Shoham-Schwartz Z, Lancet M 1988 Growth discordancy in appropriate for gestational age, term twins. Obstet Gynecol 72:582-584 
31. Pharoah PO, Cooke RW 1997 A hypothesis for the aetiology of spastic cerebral palsy-the vanishing twin. [Review] Dev Med Child Neurol 39:292-296

32. Scheller JM, Nelson KB 1992 Twinning and neurologic morbidity. [Review] Am J Dis Child 146:1110-1113

33. Pharoah PO, Adi Y 2000 Consequences of in-utero death in a twin pregnancy. Lance 355:1597-1602

34. Pharoah PO 2001 Cerebral palsy in the surviving twin associated with infant death of the co-twin. Arch Dis Child Fetal Neonatal Ed 84 (2):F111-F116

35. Glinianaia SV, Pharoah PO, Wright C, Rankin JM 2002 Fetal or infant death in twin pregnancy: neurodevelopmental consequence for the survivor. Arch Dis Child Feta Neonatal Ed 86(1):F9-F15

36. Rydhstrom H, Ingemarsson I 1993 Prognosis and long-term follow-up of a twin after antenatal death of the co-twin. J Reprod Med 38:142-146

37. Lin IJ, Chen CH, Wang TM, Fu LS, Chi CS 1999 Infants of twin pregnancies with one twin demise in the uterus: a retrospective study. Taiwan Erh Ko I Hsueh Hui Tsa Chih 40:92-96

38. Saito K, Ohtsu Y, Amano K, Nishijima M 1999 Perinatal outcome and managemen of single fetal death in twin pregnancy: a case series and review. J Perinat Med 27:473-477

39. Sonneveld SW, Correy JF 1992 Antenatal loss of one of twins. Aust N Z J Obste Gynaecol 32:10-13

40. Petersen IR, Nyholm HC 1999 Multiple pregnancies with single intrauterine demise. Description of twenty-eight pregnancies. Acta Obstet Gynecol Scand 78:202-206

41. Emery ES, Eaton A, Grether JK, Nelson KB 1997 Assessment of gestational age using birth certificate data compared with medical record data. Paediatr Perinat Epidemiol 11:313-321

42. Sinha G, Corry P, Subesinghe D, Wild J, Levene MI 1997 Prevalence and type of cerebral palsy in a British ethnic community: the role of consanguinity [see comments]. Dev Med Child Neurol 39:259-262

43. Roberts L, Pilcher L 2001 National Perinatal Epidemiology Unit 2000 Annual Report Oxford, Institute of Health Sciences

44. Pharoah PO, Cooke T, Cooke RW, Rosenbloom L 1990 Birthweight specific trends in cerebral palsy. Arch Dis Child 65:602-606
45. Pharoah PO, Cooke T, Johnson MA, King R, Mutch L 1998 Epidemiology of cerebral palsy in England and Scotland, 1984-9. Arch Dis Child Fetal Neonatal Ed 79:F21F25

46. Dowding VM, Barry C 1988 Cerebral palsy: changing patterns of birthweight and gestational age (1976/81). Ir Med J 81:25-29

47. Hagberg B, Hagberg G, Olow I 1993 The changing panorama of cerebral palsy in Sweden. VI. Prevalence and origin during the birth year period 1983-1986. Acta Paediatr 82:387-393

48. Topp M, Uldall P, Langhoff-Roos J 1997 Trend in cerebral palsy birth prevalence in eastern Denmark: birth-year period 1979-86. Paediatr Perinat Epidemiol 11:451-460

49. Topp M, Uldall P, Greisen G 2001 Cerebral palsy births in eastern Denmark, 1987-90: implications for neonatal care. Paediatr Perinat Epidemiol 15(3):271-277

50. Takeshita K, Ando Y, Ohtani K, Takashima S 1989 Cerebral palsy in Tottori, Japan Benefits and risks of progress in perinatal medicine. Neuroepidemiology 8:184-192

51. Parkes J, Dolk H, Hill N, Pattenden S 2001 Cerebral palsy in Northern Ireland: 1981-93. Paediatr Perinat Epidemiol 15(3):278-286

52. Anonymous Surveillance of cerebral palsy in Europe: a collaboration of cerebra palsy surveys and registers 2000 Surveillance of Cerebral Palsy in Europe (SCPE). Dev Med Child Neurol 42(12):816-824

53. Meberg A, Broch H 1995 A changing pattern of cerebral palsy. Declining trend for incidence of cerebral palsy in the 20-year period 1970-89. J Perinat Med 23:395-402

54. Haerer AF, Anderson DW, Schoenberg BS 1984 Prevalence of cerebral palsy in the biracial population of Copiah County, Mississippi. Dev Med Child Neurol 26:195 199

55. MacGillivray I, Campbell DM 1995 The changing pattern of cerebral palsy in Avon. Paediatr Perinat Epidemiol 9:146-155

56. Riikonen R, Raumavirta S, Sinivuori E, Seppala T 1989 Changing pattern of cerebral palsy in the southwest region of Finland. Acta Paediatr Scand 78:581-587

57. Rumeau-Rouquette C, Du MC, Mlika A, Dequae L 1992 Motor disability in children in three birth cohorts. Int J Epidemiol 21:359-366

58. von Wendt L, Rantakallio P, Saukkonen AL, Tuisku M, Makinen H 1985 Cerebral palsy and additional handicaps in a 1-year birth cohort from northern Finland-a prospective follow-up study to the age of 14 years. Ann Clin Res 17:156-161 